\title{
BUT ALSO FULL OF SEEDS FOR A FUTURE THAT COULD HAVE TURNED OUT DIFFERENTLY
}

\author{
By \\ Megan Marie Bickel \\ B.F.A, Art Academy of Cincinnati, 2012
}

\begin{abstract}
A Thesis
Submitted to the Faculty of the

College of Arts and Sciences of the University of Louisville In Partial Fulfillment of the Requirements for the Degree of
\end{abstract}

Master of Fine Arts

In Studio Art and Design

Hite Art Institute

University of Louisville

Louisville, Kentucky

May 2021 

BUT ALSO FULL OF SEEDS FOR A FUTURE THAT COULD HAVE TURNED OUT DIFFERENTLY

\author{
By \\ Megan Marie Bickel
}

A Thesis Approved on

April 2, 2021

By the following Thesis Committee

Tiffany Calvert

John Gibson

Christopher Reitz

Ché Rhodes 


\title{
ABSTRACT \\ BUT ALSO FULL OF SEEDS FOR A FUTURE THAT COULD HAVE TURNED OUT DIFFERENTLY
}

\author{
Megan M Bickel
}

April 2, 2021

This thesis examines the relationship between "illusion," "allusion," and their relationship to contemporary images which announce, shield, or reference information. Beginning by discussing Casualist and Post-Digital Painting discourse, two styles I work within, we see connecting tissue in announcing and shielding of meaning. We look at the meaning of marks, and in the parallel exhibition, marks that utilize camouflage strategies appear as a metaphor for illuding to information which appears as conveying depth when there is none and using paintings' symbols in objects that are not paintings. The work 'alludes' to what the viewer has seen before and relies on semiotics to reference contemporary events and painting. Discovering the oscillating development of camouflage (that utilized paint, assemblage, and textiles), surveillance photography, and the screen, we see that the materials that make up this exhibition have an eerie tie to warfare, and thus we begin to look at the holographic textile, also appearing here, as a 
utopian object that did not evolve within military technology. The use of

holographic textiles, then, becomes the ethical solution to critiquing illusion and allusion in contemporary images due to their lack of incorporating images of oppressed or victimized communities to profitize news organizations, as one example.

This thesis uses the writing styles of philosophy, critical theory, and social sciences to discuss these findings above. Meaning, we will take a lengthy amount of time introducing the various literature that this thesis contributes to and so it may at times feel like three different areas of research. This is by design, as this document serves to conclude my Master of Fine Arts studies whilst benefiting my future studies in the Digital Humanities. 


\section{TABLE OF CONTENTS}

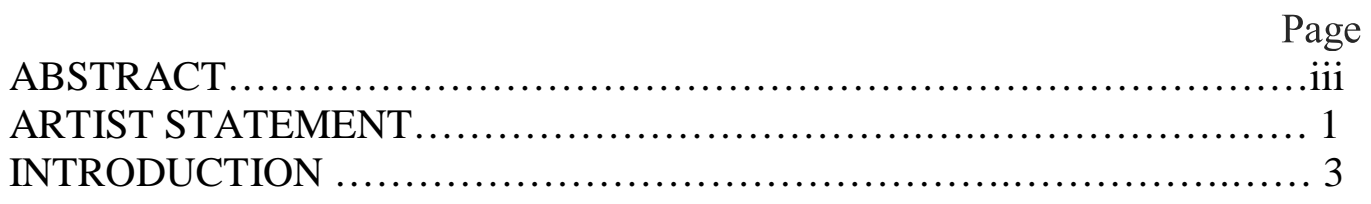

Literature Review

Casualist and Improvisational Painting .................................. 8

Painting as Indexical Act: If Marks Mean Feelings .......................... 17

Isabelle Graw and Indexical Painting ....................................... 18

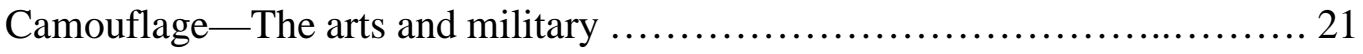

The advent of misdirection and visual (data) information ....... 23

Camouflage and Surveillance Photography: meaning hidden,

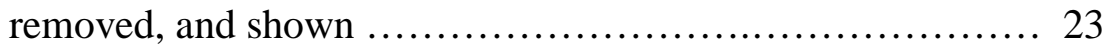

Camouflage and Casualism .................................. 25

Introduction to New Media: LevManovich: .................................. 27

The Screen and the User ..................................... 28

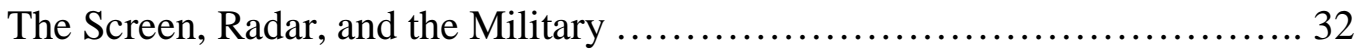

Villem Flusser: Traditional and Technical Images .............................35

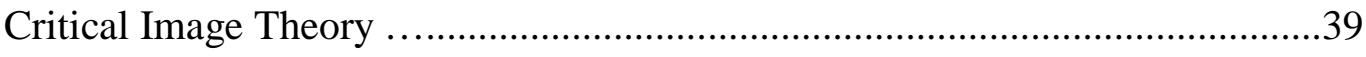

Conclude Relationship: Painting, The Military, and The Screen ................42

Analysis Post-Digital Painting .............................................43 
Copying Digitality: Holographic Textiles, Light Misdirection, and Utopian Anti-

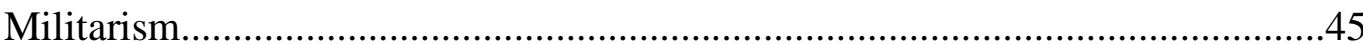

What About the Twenty-Second Cetury? ..................................48

Defining Utopia ......................................................49

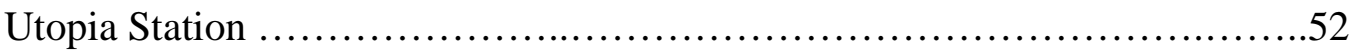

What about the Twenty Second Century, Conclusion ........................59

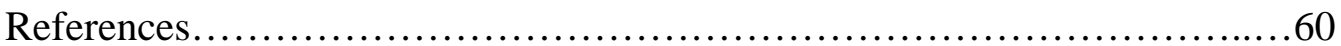

Curriculum Vitae......................................................64 


\section{ARTIST STATEMENT}

I am meditating on two words as they relate to one another in our current moment: illusion and allusion. Specifically, how we consume visual data, the probability of factual 'truths,' and cultivating safe, imaginative spaces for the viewer to conceive ethically superior realities.

Illusion references a trick and has a visual connotation. The

illusion typically describes the realistically rendered image, and its historical etymology links to painting -- and thus propaganda. Illusion references the desire to convince a viewer of something. In the corresponding body of work, camouflage tactics function as a metaphor for showing and hiding meaning. Balancing repeating painterly marks with masked off negative shapes, painted on synthetic holographic fabrics, painterly depth, and illusionistic space engage more significant issues of misinformation and the trustworthiness of images. On the other hand, an allusion is primarily literary and depends on the viewer's imagination.

Interestingly, 'illusion' and 'allusion' display a particular power dynamic between purveyors of visual and purveyors of written information.

Here, the power dynamic that I am referencing can at times appear malignant. Meaning, for the illusion, that there is a historical power to deceive in a way that may appear psychologically threatening when considered by the viewer. This threat's evidence does not appear in the allusion because in the act of reading a text, the viewer (or reader) is reliant on their imagination. Thus, all the conjured imagery or ideas that arise during reading are contingent on what they have consumed prior; this illuminates 
that images manipulate the viewer, and more frequently due to our use of the internet as a source for knowledge, news on current events, and socialization. At times appearing indecisive, I prefer to use the viewers' surprise and subject referential media to offer the audience a summated opportunity to consider misinformation, specifically in the Digital Age.

Whereas my studio work activates all the above, this document expands these interests to cover the effect of misinformation and the historical connections. With my use of holographic textiles and digital media such as screen recordings, photoshop, and no cost 'glitching' software, we engage with the historical connections between painting, textile, photography, and the screen, all being affected by military technology. Using the semiotics of Casualist and Post-Digital Painting, I activate painting, textile, digital media, installation, and curation to create objects and scenarios that depict the effect of our experience with digital media. 


\section{INTRODUCTION}

but also full of seeds for a future that could have turned out differently is a document that broadly covers mimesis and deception within painting and the screen and the synaptic relationship between the two and military enterprise.

This examination contains a dissected focus between (1) the indexic properties of contemporary painting that operates in both the Casualist and Post-Digital manners and their connection to the screen; and (2) the synaptic connections between military advancement and painting, textiles, radar, and the screen. From here will be my investigations into holographic technology as the ultimate object of deception and utopian desire due to its lack of military evolution. This text, as a preface, is going to spend a lot of time defining terms.

This discussion will begin with a literature review defining Casualist painting, also referenced as here 'Provisionalism,' Casualism is an approach to abstract painting that (1) questions the fetishized value of artistic labor, (2) expands, (3) de-skills and deknowledges abstraction to combat its commodity status. It is essential to define these terms as there is a deficit of their appearance within academic discourse. Then, we will (2) introduce the neo-Marxist / neo-Psychoanalytic approach to analyzing painting presented by Isabelle Graw that proclaims that it is in the various methods to mark-making in abstraction that we can find a meaning that is culturally relevant to the zeitgeist. This lens assesses the social value or significance in the literal deconstruction of value and material found in Casualism. 
From here, we will investigate how knowledge of indexical mark-making, as per Graw's observations, can allow us to be aware of the artists' body in relationship to contemporary painting. The body, of course, has a connection to all forms of rectangular imagery regardless of their presentation - analog, digital, or through

projection. The critical difference in the body's relationship to the image is the difference in making or viewing. There is an experiential difference in the haptic nature of creating images and the viewer's experience of hapticity in consuming them. At risk of sounding mystical, the body contains the energies of anyone making a mark. Psychological experience can be documented in how individuals move their bodies in space - posture and pace are a few examples. As a liquid is applied to a surface using force from a body or a tool dictated by a body, the energies that become evident in surfaced painting indicates how the artists' body holds specific emotions. For the viewer, the context of an image all predicates their relationship to an image.

As we will discuss in "Camouflage: The Arts and the Military," there is a link between materials throughout this exhibition: military use. Here, camouflage development in the U.S. Military renders a metaphor, and so camouflage becomes a signifier. The development of camouflage relied on a deconstruction of meaning, specifically visual legibility regarding an objects' relationship to the space it existed within. When looked at philosophically, it becomes an examination of how meaning is hidden or ascribed in nature. This act works as a visual metaphor or paradigm to observe the differentiation of 'illusionistic' meaning and 'allusionistic meaning. Its development was a consequence 
of the advent and introduction of photography and airplanes within surveillance and reconnaissance. Later, it also had to respond to radar and screens.

Next, we will finally describe the links between Casualism and camouflage through the lens of Isabelle Graw's analysis: that this key of illusion and allusion is derivative of the shielding, announcing, and misdirection of meaning that is present in both. Camouflage as described in the last paragraph and Casualism in the decisive mark-making, structure design (or lack thereof), and material usage. The mark here feels inextricably tied to the appendages and tools that make the mark. Here is where we begin to discuss the screen, as well as photography. This section is of importance as we start to elaborate on the importance of tools as predictors for ways of making - which is an extension of Graw's indexicality of making. As much as a mark's appearance can indicate the artist's dynamic presence, a tool such as a camera predicates the image.

When considering Casualism referentially to this exhibition (and later PostDigital painting), we must look at the advent of the screen and its relationship to the military akin to our examination of camouflage to painting and meaning. We will discuss the use of photography in the military and its cultivation and connection to radar and the screen. For this section of the discussion, we rely heavily on the theorems and histories provided by Lev Manovich. Manovich, a cultural analyst and new media theorist who stipulates that the connecting tissue between understanding the body's response to images and contemporary modalities of meaning in images is the relationship, or indexic qualities, that physically connect bodies and flesh to our digital landscape. 
This text uses the theoretical genealogy of keys and buttons according to Vilem Flusser in the same way that we used the genealogy of the screen according to Manovich. I take time to discuss the advent of the screen in the military because it contributes to our examination of tools and the indexic meaning of images discussed indepth and in response to Flusser. Flusser was a Brazilian Czech-born philosopher, journalist, and photographer. His authorship was heavily reliant on Martin Heidegger, existentialism, and phenomenology. Later, his work, which we rely on here, began to use these guiding perspectives to discuss the philosophy of communication and artistic production. His photography background helps ground his theories in using tools and buttons as necessary codes of production that distance the maker of an image from that which is being captured. These observations accumulate to define what Flusser refers to as the distinction between traditional and technical images. This anthropological perspective argues that before the invention of language, or written language specifically, the image communicated most effectively. With the advent of written language, the image became different. The image was relied upon to share extraneous information that was important for those in power to communicate to illiterate masses: thus propaganda. Flusser, here proclaims that with the advent of the screen and our reliance on it, the image now has a different purpose. The image is designed in response to language. According to Flusser, meaning is thus codependent and intertwined.

Here we will conclude our introduction to (1) Casualism, (2) indexic mark making, (3) camouflage and the advent of misdirection and their relationships to painting, and (4) their codependence with surveillance the camera, radar, and the screen. This conclusion will be wrapped up by a brief look at critical image theory - as it's the most 
relevant modality to consider this topic. All this elaborate 'introducing' will provide context for the later half of the text which covers an introduction to (1) Post-Digital Painting, a contemporary style of painting that responds to the advent of digital tools and the conceptualization of digital "spaces." Then (2) "Copying Digitality" is a look at the use of holographic inkjet printing in this exhibition and an introduction to the genealogy of the hologram, and (4) the utopian properties of the hologram. Then we can, finally, (6) enter a holistic look at the use of appropriated digital media and look at indexic marks in the paintings within this exhibition to explore and introduce the concluding project of the research presented here: What About the Twenty-Second Century. 


\section{LITERATURE REVIEW}

\section{CASUALIST AND IMPROVISATIONAL PAINTING}

What we encounter in the indexical signs of painting is not so much the authentically revealed self of the painter. As indexes, these signs can suggest the (imaginary) presence of the absent artist. Painting is, in other words, a highly differentiated language that consists of several techniques, methods, and artifices, which allow for the fabrication of the impression of the author's quasi-presence as an effect. Many artists are aware of these instruments and their suggestive power, using them deliberately or ironically to produce and mock this effect. Like a bone, anything that is stretched or fractured doesn't heal - but instead endures pain and frustration for years. It doesn't allow for anything imaginatively new, only fortified renditions of what has been made prior. The terms "Provisionalism," "Casualism," and "Post-Digital Painting" are stylistic modes of operation within Painting that I align my work within. This literature review is essential to include, other than for the apparent reason of defining inclusion within the painterly conversation. Together, these styles form a critique of the problematic contribution textiles, paint, and digitality has been designed in response to warfare. Stylistic modes of operation within Painting that I align my work within. This literature review is essential to include, other than for the apparent reason of defining where I feel I belong within the painterly conversation, but also because they, together, form a critique of the problematic contribution textiles, paint, and digitality have been designed under or in response to warfare. 
Casualist painting has been birthed, debated, and expanded upon via a few select and beautiful writers. We will look at its genealogy through various blogs such as Two Coats of Paint and Abstract Critical and two major publications: The Brooklyn Rail and Art in America.

In 2009, Raphael Rubenstein published "Provisional Painting" in Art in America. ${ }^{1}$ He described a 'new' mode of painting: a provisionally in painting [appearing] in works that look casual, dashed-off, tentative, unfinished, or self-canceling by artists that have been working this way for years: Albert Oehlen, Raoul de Keyser, Christopher Wool, and Mary Heilmann to name a few. Rubenstein cites that this is just another moment in modern painting that is emblematic of painterly admonishment of the statusquo. He includes Cezanne's Mont St. Victoire, Dadaism, Artaud's call for "no more masterpieces," punk music, and Richard Tuttle's 'humble compositions.' Why are we surprised that painters are skeptics of painting after the turn of the $20^{\text {th }}$ century, World War One, and Postmodernism? Is there a doubt that painters lack self-awareness that the way they spend their time is selfish? Our precious time sitting in a room, preferably alone, staring at things that we have made that have no objective purpose beyond existing? Of course painters keep revisiting the selfdiagnosed disenchantment of their medium. To refer to Rubenstein: Why are we surprised that painters are skeptics of painting after the turn of the $20^{\text {th }}$ century, World War One, and Postmodernism? Is there a doubt that painters lack foundational selfawareness that the way they spend their time is kind of selfish? Our precious time sitting

\footnotetext{
${ }^{1}$ Raphael Rubinstein, "Provisional Painting," ARTnews.com (Art in America, September 29, 2014), https://www.artnews.com/art-in-america/features/provisional-painting-raphael-rubinstein-62792/. Accessed 2020.
} 
in a room, preferably alone, staring at things that we've made that have no objective purpose beyond that of existing? Painters keep revisiting their selfdiagnosed disenchantment of their medium. To refer to Rubenstein:

The genealogy of what I refer to as provisional painting includes Richard Tuttle's decades-long pursuit of humble beauty, Noël Dolla's still-radical stained-handkerchief paintings of the late 1960s, Robert Rauschenberg's "cardboards" of the 1970s, David Salle's intentionally feeble early canvases and the first-thought/best-thought whirlwind that was Martin Kippenberger. I take such work to be, in part, a struggle with a medium that can seem too invested in permanence and virtuosity, in carefully plannedout compositions and layered meanings, in artistic authority and creative strength, in all the qualities that make the fine arts "fine." As employed by younger artists, provisionality may also be an attempt to disregard the blandishments of the art market—what seemed, until only yesterday, an insatiable appetite for smart, stylish, immaculately executed canvases, paintings that left no doubt as to the artist's technical competence, refined sensibility, and solid work ethic.” This may also be an attempt to spurn the blandishments of the art market—what seemed, until only yesterday, an insatiable appetite for smart, stylish, immaculately executed canvases, paintings that left no doubt as to the artist's technical competence, refined sensibility, and solid work ethic. ${ }^{2}$ Here, Rubenstein's contributions to the field are foundational and critical, but never clarifies whether he sees the connection between dispraising formalist values and

\footnotetext{
${ }^{2}$ Rubenstein, "Provisional Painting." 2009
} 
a critique of painting's contribution and participation in Capitalism. To avoid speculation, I will just acknowledge I find this problematic, but you cannot discuss Casualism without acknowledging Rubenstein as a founding author of the discourse.

The following term I will be introducing, "Casualism," relates to the "Provisionalism" described by Rubenstein. The terms may seem estranged, but when examined closely, have several commonalities. Mirriam-Webster defines "provisional" to mean "serving for the time being,"4 implying that these paintings have a temporary nature, but Rubenstein never states that that is what he means when he classifies this style of work as "provisional." ${ }^{3}$ Yes, there are numerous references to modernism's strategies of refusal and acts of negation - but neither "refusal” or “negation” share an implication of provisionality. An assumption that a painting designed to look unfinished is not being misleading. It is incomplete. It is temporary; the artist sure to change their mind during possession of that work.I prefer Butler's "Casualism” as it accurately notes the distinction of intent. 'Casualism’ refers to a lack of formality, a deconstruction of expectations. Since painting holds a remarkable amount of expectations due to its longevity and use through history, part of a deconstruction of its form is to embrace deconstruction.

A painter and arts writer, Sharon Butler is widely known as the founder of Two Coats of Paint. In 2011, after a self-reported 'lengthy dialogue' with friends and colleagues, Sharon Butler published "The New Casualist," in the Brooklyn Rail. ${ }^{4}$ At the time she described this newfound style as assessing "basic elements like color,

\footnotetext{
3 “Provisional.” Merriam-Webster.com Dictionary, Merriam-Webster, https://www.merriamwebster.com/dictionary/provisional. Accessed 17 Mar. 2021.

4 “Boilerplate Biography.” https://sharonlbutler.com/brief-biography
} 
composition, and balance, based on 1920s-vintage Bauhaus principles taught in every 2D foundations course. [In this action] they are looking for unexpected outcomes rather than handsome results. ${ }^{5}$ Dashing our expectations of "good painting," painters like Martin Bromirski, Patricia Trieb, Patrick Brennan, Jered Sprecher, and Keltie Ferris have challenged their validity and thus moved painting in a direction that requires a different way of looking. If a painting seems lousy, with a poorly constructed support and amateurish paint handling, look again." ${ }^{6}$

Butler revisited the subject in 2014. This time around, newfound selfrealization cultivated an honest assessment. In 2011 did not state she was a painter working within this modality. Within the safety of her blog, Two Coats of Paint, Butler permits a descriptive vulnerability that reads truthfully to the approach.

"What distinguishes a Casualist approach is the premium on unexpected outcomes rather than handsome results. This approach translates into comfort with inconsistency and a willingness - manifested in departures from conventions of color, composition, texture, material, and balance - try not to impose harmony on elements that may not be naturally susceptible to it." ${ }^{7}$

The Casualist impulse has yielded compositionally awkward work that may seem humble and selfdeprecating, additionally employing 'hobbyist' prefabricated materials like pre-stretched canvases and canvas board. Though often small in scale, the work might spill into three dimensions because the stretchers loom just as large aesthetically as the paint itself. The most compelling casualist work has an anti-heroic, offhand feel and ostensibly shows

\footnotetext{
${ }^{5}$ Sharon Butler. "The New Casualists.” The Brooklin Rail. June 2011 https://brooklynrail.org/2011/06/artseen/abstract-painting-the-new-casualists Isabelle Graw, ” The Value of Liveliness: Painting as an Index of Agency in the New Economy.” Painting Beyond Itself: The Medium in the Post-medium Condition. Sternberg Press, 2016. P79-101. P 93.

${ }^{6}$ Butler, 93.
} 
little attention to craft or detail. Unsurprisingly, galleries and collectors have been slow to embrace this type of work because it seems too easy. Some old-school painters have branded the most obvious approaches 'crapstraction. ${ }^{17}$

Butler notes the genealogical similarities between Provisionalism, introduced above by Rubenstein, with this new Casualism. Later relating the chronological attachment to Minimalism's ethos of material as meaning - and the subsequent Feminist response by the likes of Elizabeth Murray, Mary Kelly, and Ree Martin (to name just a few) who fought to re-invigorate Minimalist tendencies with the messiness of the everyday experience. Importantly also, her mentioning of Richard Tuttle and Raoul de Keyser's intentional fight against ambition. As Butler suggests, the genealogy, or DNA, ${ }^{9}$ connects Casualism and Provisionism to Arte Povera, Dadaism, Art Informal, and Arte Brut. Though yes, I emphatically agree with this genealogy assessment; the anticapitalist and Marxist analysis found layered on thick in Butler's interpretation misses a crucial point. Casualist or Provisional paintings are also inextricably tied to the painterly impulse to respond to the Postmodern death of painting. In Peter Geimer's" Painting and Atrocity: The Tuymans Strategy" (2012), he discusses the redundancies of depicting media images or news stories using a painterly idiom, when there are so many other options available; and takes a moment to diverge and just simply dives ${ }^{10}$ of Gerhard Richter, Luc Tuymans, Polke, Keifer, Haley, and Ross Bleckner to name a few. Resulting in a quote that I find just as applicable for discussing Casualist discourse. He quotes Helen Molesworth, American curator, and

\footnotetext{
${ }^{7}$ Butler, "The Casualist Tendency." Two Coats of Paint. 2014. https://www.twocoatsofpaint.com/2014/02/the-casualist-tendency.html. Accessed March 2021.
} 
observes correlations between the depiction of historical events with paint and subconscious response to the engrained loss from the" death of painting" after abstraction:

"Tuymans broke from his postmodern predecessors' engagement with representational painting, a body of work characterized by the powerful newKantian conception that the primary task of modernist painting was 'precisely the working through the end of painting.' These artists (such as Richter, Polke, Anselm Kiefer, Peter Halley, David Salle, or Ross Bleckner) typically produced paintings with the affective registers of irony, sentimentality, belatedness, or mourning." 8

To continue, Geimer summates Molesworth's quote by observing that [Tuymans] does not "merely paint from photographs or to them; instead, his paintings work against the spatial logics of both systems of representation. ${ }^{12}$ Of course, to some extent, this feels hyperbolic and at risk of psychoanalyzing the artist. Still, there is something to ponder regarding the effects of trauma and the painters making work deemed Casualist or Provisional. If you 'studied' within the studio art pedagogical system from 2001 to 2015, you have been informed that with Abstract Expressionism and Pop Art, painting became flexible to rendering in the1930s . . but then around the mid-1980's it died. ${ }^{14}$ And came back again. And died again. For those studying Painting with that daunting capital "P," you begin to wonder where the value is. It is fair to expect to mourn your medium when you seek a professional certification of

\footnotetext{
${ }^{8}$ Helen Molesworth, "Luc Tuymans: Painting the Banality of Evil." in Luc Tuymans, ed. Madeline Grynszteijn and Helen Molesworth. (San Francisco: San Francisco Museum of Modern Art,2009),19.
} 
that medium. It may even cultivate some dissonance or resistance to said medium. An aesthetic composed of doubt, questioning, or deconstruction of painterly idioms certainly feels like a solution.

This mourning referenced above, combined with its era of inception (the late 2000s and early 2010s), are factors to consider in the development of Casualism. Historically speaking, Butler's observation regarding the fetishized commodity of painting in 2014, felt timely. It was the 'end' of the Great Recession in the United States, the beginning of the Arab Spring, and Occupy Wall Street. ${ }^{15}$ For workers (in this case painters, if painters are a part of an elite labor force that contributes to the expansion of capital of the $1 \%$ ) that contribute to the fetishized commodity of painting, a straightforward way to contribute to destabilizing that participation is to eliminate the (1) romance associate with their making, (2) eliminate the perception of skill and labor of the artist that is so fetishized. Instead: make things that are understood communally as unsuccessful, on purpose.

The criticism is predictable - but its sole author is surprising. In 2015, a year after Butler's text is introduced to the internet, Alan Pocaro publishes a critique, "Provisional Painting: Three Hypothesis" in a small online periodical, since disbanded, Abstract Critical. ${ }^{9}$ For the sake of transparency, Pocaro was a professor of mine during my undergraduate studies at the Art Academy of Cincinnati, and I found his instruction invaluable. In his critique of Casualism or Provisionalism, he found fault with this progression or re-emergence of abstract painting, ascribing its aesthetics a failure, but

\footnotetext{
${ }^{9}$ Alan Pocaro. "Provisional Painting: Three Hypothesis." Abstract Criticial. Jan 2015. https://www.alanpocaro.com/writing/2015/2/15/provisional-painting-three-hypotheses. Accessed March 2, 2021
} 
also found fault with the 'type of student' that tended to make that type of work. That student being, according to Pocaro, more interested 'living the life' of an artist, than putting in the labor of being an artist. Pocaro assumes that these students, not interested in feigning romanticized labor within the studio, simply weren't interested in the work only the social capital rewarded to those designated 'artist.' This argument relies on ideas such as Pierre Bourdieu's theory of cultural and social capital, right? Cultural capital implying that being aware of specific standards and practices can elicit financial (and social) rewards in life. ${ }^{10}$ In contrast, social capital renders valuable economic mobility and saves people time and resources when access to specific skills becomes rarified. An example being the quick phone call to your friend, the pediatrician, when your child is ill at 2 a.m. versus having to wait to call in the morning or, worse, an unnecessary and costly visit to the emergency room.

It poses a weak argument, a tired one typically posed by those working outside the field. It is an argument that Art needs to be poured over. The practice necessitates expertise; requiring implicit and voluntary suffering of the artist - this is romantic at best. Arguing that failure, haste, urgency, and de-skilling are all topics void of discussion / value.

To conclude, Casualism is an observance of agency and rebut against the trouble with painting. The crisis we reference is the participation with the marketplace. To clarify why making something poorly may be indexic to the intention or guilt of the author, I will point to the theory of indexical agency of

\footnotetext{
${ }^{10}$ Xiaowei Huang. Understanding Bourdieu - Cultural Capital and Habitus. Review of European Studies. 45. 2019. 10.5539/res.v11n3p45
} 
the painter that appears in a unique way separate and individual from other forms of making. 


\section{PAINTING AS INDEXICAL ACTS: IF MARKS MEAN FEELINGS}

All aesthetic practices employ systems of signs and therefore contain a semiotic dimension. In 2016, Isabelle Graw and Ewa Lajer-Burcharth compiled, in response to recent developments in pictorial practice and critical discourse, Painting beyond Itself: The Medium in the Post-Medium Condition. The work sought new ways to approach and historicize the question of the medium. Based on a conference at Harvard University in 2013 - the work focuses on the changing role of materiality in establishing painting as the privileged practice, discourse, and institution of modernity. In Graw's essay within the compilation, "The Value of Liveliness: Painting as an Index of Agency in the New Economy," Graw expands on this universal observation by stating that specifically in painting, there is one type of sign - indexical signs. "Indexical signs possess the physical power of pointing a finger, a power that comes close to [Pierce's] 'magnetisms. Once [indexic signs] appear in the context of the painting, they forcefully point to the absent author who seems to be somewhat physically present in them." ${ }^{11}$ This observance of the difference in a painted image versus that made by a lens is an observation of tools: the author's distance from the final image. Graw continues to elaborate that the physical form of its signs seems to get constantly emphasized in painting. In a painting, it is all of its signs - iconic, symbolic, or constructed - that evokes the presence of the absent author. ${ }^{12}$

\footnotetext{
${ }^{11}$ Isabelle Graw, " The Value of Liveliness: Painting as an Index of Agency in the New Economy." Painting Beyond Itself: The Medium in the Post-medium Condition. Sternberg Press, 2016. P79-101. P80.

${ }^{12}$ Graw, 81.
} 


\section{ISABELLE GRAW AND INDEXICAL PAINTING}

Graw's observations lend themselves to the argument that there is a psychoMarxist explanation for Casualism's rise. Yes, suppose the marks and sculptural qualities can be indebted to the body that made them. Painting has always appeared to hold its painterly specificity and indexicality, but it also holds how labor and lifetime are present within it - its value-form. Graw's argument, again, claims that since painting can produce the sensation that it has captured living labor, thus explaining its current popularity in our new economy. Our new economy, social scientists, have alternatively described, as the" Post-Fordist condition"(Paolo Virno), as "cognitive capitalism" (Yann Moulier-Boutang), or as "network capitalism" (Luc Boltanski / Eve Chiapello). What designates this new economy is that it aims at our cognitive and affective capacities. Seen from this angle, it is the way painters live that becomes commodified. $^{13}$

Graw's observations linking the documentation of the life indicative to painting to cognitive capitalism is the factor that validates it's inverse. Graw's observations validate the Casualist desire to defer from the commodification of the 'artist self.' If Casualism avoids the commodification of the self, its metaphor is shielding the painter. The painter camouflages themselves amongst the disembodied aesthetic experience. The deskilling of their production disentangles the artist's body from the viewer's experience and cognizance of the artist. I wonder if this camouflaging of the artist self also contributes to the distancing of oneself from painting: the dead medium;

\footnotetext{
${ }^{13}$ Graw, 82.
} 
an unconscious effort to relieve oneself from the pressure, quandary, or guilt entangled in the process of making paintings in the $21^{\text {st }}$ Century.

\section{In Peter Geimer's "Painting and Atrocity: The Tuymans Strategy," Geimer} assesses the connective tissue between photography, social responsibility, and abstract painting. ${ }^{14}$ Or minimally, abstract painting, that includes the medium of paint, which is void of figuration (or sometimes referential), and specifically indexic to photography and historical images. Beginning with an introduction

to Wilhelm Sasnal's Gaddafi (2011) painting, Geimer puts forth that unlike the authors of the press photographs of Muammar Gaddafi's death on October 20, 2011, Sasnal was not present at the time of this historic event. Thus, rather than depict the event itself, Sasnal focuses on the experience of being the "recipient of the imagery that circulated worldwide shortly following Gaddafi's death," much like most of the world. ${ }^{15}$ Geimer references all of Sasnal's Gaddafi works, but here we will focus purely on Gaddafi (2011). Gaddafi, unlike the rest of the series, which contains figurative renderings of photographs of Muammar Gaddafi's corpse as it lie upon a mattress centered in a supermarket refrigeration room, becomes abstracted. Lines loosely rendered to simulate a room: indicated by the three straight lines that suggest single-point perspective, a rectangle is centered with a mass of red, green, and blue 'straight-from-the-tube' pigments wildly and desperately mixed. Geimer refers to this treatment of the corpse as turning the body into pure painting: thick oil pigments with an impasto application."16

\footnotetext{
${ }^{14}$ Catrin Lorch, Historienmalerei 2.0," Suddeutsche Zeitung, February 3, 2012.

${ }^{15}$ Peter Geimer's "Painting and Atrocity: The Tuymans Strategy. "Thinking Through Painting: Reflexivity and Agency Beyond the Canvas. Sternbereg Press. 2012.

${ }^{16}$ Geimer, 17
} 
This process of inverting the effect of perceiving violence via abstraction also serves to camouflage this experience. It serves to distance the artist's personhood from experience while granting space to investigate the incident. The process of camouflaging, shielding, distancing, and ironically announcing the self (through creating a product: the painting) obtains a metaphor that feels entrenched in history. Perceived violence and media-induced trauma begs the question, "where do we find meaning, empathy, or understanding in these images and this content?" Can working with that metaphor of camouflage and abstraction be a working tool investigating where that meaning lies? In our attempt at answering that question, we will begin, here, understanding the etymology of camouflage as it is recognized today. In this understanding, we will discover that the development of camouflage and the root need of its cultivation: protection against innovative technologies in surveillance mentioned earlier. Photography and airplanes link textile, painting (i.e., visibility and hiding) with documentation and monitoring (i.e., the lens and the screen). 


\section{CAMOUFLAGE: THE ARTS AND THE MILITARY}

The term "camouflage" was absorbed into the English and American lexicon almost immediately after its introduction. Coined in 1914 by French general and artist Lucien Victor Guirand de Scovela. Entering into the English vernacular early the following year, the term "camouflage" came into being as a way to "refer to systematic dissimulation for concealment from photographic detection." ${ }^{17}$

On the one hand, "camouflage" harkens back to the nineteenth-century French word 'camouflet,' referring to a primitive land mine that creates powerful underground explosions without surface rupture or to a tiny smoke bomb that explodes when placed into the nose of an unwitting victim. "Camouflage" is also related to the medieval Italian 'camuffare,' meaning "to make up." The reference might also be not to a singular object or organism but a generalized visual aspiration. You can drape yourself in trademarked camouflage patterns to articulate military fervor or more pacifisteven anarchist-inclinations. An army or a paintball troupe wears camouflage because it offers some degree of environmental concealment in a specific condition. Still, these identical uniforms demarcate the individual as a member of a group. There is an irony here. Camouflage serves as a moniker both for blending in and for announcing oneself.

On November 11th, 1896, an American landscape painter and portraitist, Abbatt Thayer, attended the American Ornithologists Union's annual meeting at the

\footnotetext{
${ }^{17}$ Shell, Hanna Rose. Hide and Seek: Camouflage, Photography, and the Media of Reconnaissance. MIT Press. 2012
} 
Harvard Museum of Comparative Zoology. He "planned to revolutionize evolutionary biology and to prove a universal theory of protective coloration by making things—all kinds of things—-disappear." ${ }^{18}$ Thayer subsequently wrote the "Law Which Underlies Protective Coloration." Which stated the following: (1) nature's nonhuman animals are cloaked by skins that have evolved to obliterate visual signs of their presence; (2) this obliteration is not permanent. Instead, invisibility functions only at "crucial moments" of maximum physical vulnerability, and (3) snapshot invisibility, which observes that an animal is concealed for the duration of the click of a camera shutter. ${ }^{19}$ 'Snapshot visibility,' Thayer went on to describe, was focused on two principles of camouflage, or animal protective coloration. These specific visual phenomena include "obliterative countershading" and "disruptive patterning." ${ }^{20}$ In obliterative countershading, the "parts of the animal lit brightest by the sun are consistently colored darkest, while those areas generally bathed in shadows are colored lightest."29 On the other hand, disruptive patterning consists of mottled patterns corresponding to the animal.” The contours of its silhouette, resulting in an impression of not being there. Thayer concluded that "natural selection had favored organisms that visually express one or both of those traits." ${ }^{21}$

For Thayer, it was through an evolution of activities: traveling to various museums for performative lectures in New England and New York City, a developing interest in taxidermy, and the acknowledgment that photography, maybe even more than

\footnotetext{
${ }^{18}$ Rose, 26.

${ }^{19}$ Rose, 26.

${ }^{20}$ Rose, 25.

${ }^{21}$ Rose, 26.
} 
taxidermy "could be exploited in the interest in discovering, proving, and performing crucial moments of protective coloration."22 Thayer sought to replicate the experience of looking at this critical moment in an animal's life and death. From there, he aimed to discover how to become an invisible animal; by stuffing, painting, posing, and photographing them himself. In this process of advanced investigation, Thayer began mixing photography and taxidermy in his production of elaborate photomontage. These photomontages were composed of photos taken of bird specimens and the habitats where they had been killed.

\section{The Advent of Misdirection and Visual (Data) Information}

A photo album [from the British War Office's Special Works School] at the Imperial War Museum in London commemorates two years spent at an organization founded to advance the development of "special works," the code name the British War Office had given to the development of camouflage design. At the front of the commemorative album, there is an inscription in precise calligraphy: "The following photographs may help to convey some idea of the development of airplane observation and photography during the late War, which created the need for a new science — that of concealment from the air." ${ }^{23}$

\section{Camouflage and Surveillance Photography: Meaning Hidden, Removed, and Shown}

From 1917 to 1919, photographers, painters, sculptors, set builders, sewists, and engineers worked within the Special Works School, a secret and a showpiece, a site of revolutionary practice and intense speculation. Through the advent of this new science

\footnotetext{
22 Rose, 39.

$23{ }^{31}$ Hannah Rose Shell. "Mending the Net: Camouflage, Serial Photography, and the Suture of SelfEffacement and Reconnaissance." Hide and Seek: Camouflage, Photography, and the Media Reconnaissance. Zone Books, New York City. 2012. p 77- 126. P 77
} 
were several significant observations. Materially, one of these was the use of netting-the same material used to catch fish. Netting became the most prevalent form of strategic concealment employed during World War I, but it also appeared to be the most effective. "Viewed from above — from the perspective of airplanes overhead — the forms and patterns of the netting seemed to disappear. Instead, only soft, rolling curves and shadows of pastures, fields, and woodlands appeared." ${ }^{24}$ Notably, this netting altered the appearance of lands gliding below the airplane. Still, importantly, with netting being clothing for the earth, it was made to hinder the derivation of meaning from change serially, measured over time. Designed to stem the power of photography and to mar the confidence of photographic analysts to interpret what they saw, WWI's mixed medianetting thus served as a framework for both the environment and individuals. The net was once primarily a harvesting technology; now it was a framework-a flexible grid counterpoised by aerial photography's grid. ${ }^{25}$ When garnished and installed correctly, nets made it hard, if not impossible, to interpret a visual field effectively, undermining photographic reconnaissance.

Netting, then, is the new fabric of warfare, inextricably tangled and entrenched in the technology-driven transformation of military intelligence. Thus, netting became fabricated in conceptual proximity to surveillance and reconnaissance systems, which had remained distinct governmental and military exercises. Until this point, surveillance methods were developed to watch over individuals or groups that those in power deemed suspicious: prisoners of war, psychiatric patients, prisoners, or factory workers all a la' Foucault's The Birth of the Prison. For all sins real, imaginary, or

\footnotetext{
${ }^{24}$ Shell, 81.

${ }^{25}$ Shell, 81-2.
} 
hallucinatory, they were watched. Reconnaissance, in contrast, referred to the more impersonal practice of surveying territory. Militarily, it centered around exploration on foot or horseback of an area's layout and resources before its invasion. Until World War I, with the introduction to the airplane, then ominously referred to as "the machine." Reconnaissance could be performed and communicated through field sketches and rely on 'signs' from the area -- communicating with signs instead of thoroughly representational drawings of field reports. The airplane, thus, reconfigured warfare from the top down. Bombs dropped aerially. Therefore, field reporters began showing up for work with their cameras rather than their trusty notebooks. ${ }^{26}$ Entangled in this activity of documentation was the counteraction of shielding on the ground. Camoufleurs crafted their ground cover and undermined these advances. Since netting often included painted depictions of large blocks of shapes (appearing as buildings aerially), trees, shrubs, and other fauna, a tree from an airplane was, potentially, not a tree at all.

As Hanna Rose Shell brilliantly describes in Hide and Seek, "doubt subverted certainty that a thing must function as it appears to function." 27

\section{Camouflage and Casualism}

Throughout World War I further technological advances in photographic analysis spurned counter advances in camouflage. In "Thayer's laboratory of the world, the instantaneous photograph ruled as an arbiter of camouflage construction." ${ }^{28}$ With the advent of camouflage netting, the viewed had become active agents, operating to conceal

\footnotetext{
${ }^{26}$ Hall, 85.

${ }^{27}$ Shell, 86.

${ }^{28}$ Shell, 121.
} 
themselves within regulated and serially photographed time, for the material was a skin in a kinetic and enduring sense. The viewer was in motion, as 'the machine 'moved through the skies, and as the interpreter analyzed a series of photographs after the fact. ${ }^{29}$ Hall makes a great observation that this continual evolution in technology continuously made each prospective agent (photographer, pilot, and camouffleurs) constantly aware of and necessitated a projection of the other. On the ground, hiding was only possible if you thought about your prospective place from the sky. If above, you continuously had to learn new symbols, potential misdirections, and a skilled detrusting.

${ }^{29}$ Shell, 123. 


\section{INTRODUCTION TO NEW MEDIA: LEV MANOVICH}

All of this because "images are significant surfaces, with their significance on the surface.” ${ }^{30}$ According to Vilem Flusser, images signify out there in space and time that they must make comprehensible to us as abstractions (as reductions of the four dimensions of space and time to the two-dimensional surfaces' edges). ${ }^{31}$ This "specific ability to project them back into space and time is what is known as 'imagination.' It is the precondition for the production and decoding of images."

The computer screen, noted by Lev Manovich, who we will introduce in a moment, was also developed for military use - its history having to do with military surveillance. "The history of modern surveillance" is linked with the camera and aero technology, and these "technologies begin with photography. With the advent of photography came an interest in using it for aerial surveillance." Manovich discusses this subject by introducing Felix Tournachon Nadar, an eminent photographer working in the nineteenth century, who was the first to expose a photographic plate at "262 feet over Bievre France in 1858."132

Lev Manovich, a leading theorist of digital culture and data scientist, wrote The Language of New Media in 2001. Here, Manovich explores new media's language by contextualizing it in the history of modern visual and media cultures,

\footnotetext{
${ }^{30}$ Vilem Flusser. Towards a Philosophy of Photography. Originally published in German, 1983. Englishlanguage translation, Reaktion Books, London. 2000. Pg 8-14. p8

${ }^{31}$ Flusser, 8.

${ }^{32}$ Flusser, 8.
} 
investigating how new media relies on older cultural forms and languages, inquiring into how it breaks with them. ${ }^{33}$ Here, what is relevant are his specific explorations regarding new media objects' (1) ability to create an 'illusion of reality' and their capacity to (2) address the viewer. Metaphorically, creating an 'illusion of reality' and 'addressing the viewer' recalls the action of announcing or misdirecting place from the perspective of the camouffleur during the evolution of camouflage discussed above. Our digitality is rooted in an understanding of presenting information and disguising information that is referential to our history described above and our present digital experience.

The Screen and the User

In this next chapter, we will look at a couple of theories that, combined:

confirm the connection between illusion and allusion. Images made and consumed at this point in history do one of two things: convince or reference. "Contemporary humancomputer interfaces offer radical new possibilities for art and communication. A computer monitor connected to a network becomes a window through which we enter places thousands of miles away. With the help of a mouse or a video camera, a computer can be transformed into an intelligent being capable of engaging us in dialogue." ${ }^{134}$ Referring to camouflage, the interlaced developments of photography and camouflage always necessitate the bodies of soldiers, camouffleurs, pilots, and photographers. The development of all these technologies relied upon and predicated that

${ }^{33}$ Manovich, Lev. "The Screen and the User." The Language of New Media. MIT Press. 2001.

${ }^{34}$ Manovich, Lev. "The Screen and the User." The Language of New Media. MIT Press. 2001. P 94 
bodies were involved. So, what is the relationship? What is the relationship between the desire to conceal or alter meaning and the desire to find meaning? ${ }^{35}$ It is important to remember the screen meditates' physiological effect. When, as we see here, that the viewer's body must become fixed to participate with a screen, the data presented on said screen becomes something that happens to us.

As mentioned above, the description of a screen is equally suited for

Renaissance painting. It is then not accidental that the two main computer display

formats point to two genres of painting. A horizontal format is referred

to as 'landscape mode,' whereas the vertical format is titled 'portrait mode.' 'The key

difference here is the objects' scale fluctuating from passive to aggressive. A painting is

inherently inactive; it does not derive any skill or ability other than

existing. Depending on its placement, it can be as fallible as the method of installation.

A history painting of grand magnitude is made fallible by the nail with which it stands.

\footnotetext{
${ }^{35}$ Within a footnote on Manovich's text he describes his analysis as "focusing on the continuities between the computer screen and preceding representational conventions and technologies. For alternative readings that take up the difference between the two, see the excellent articles by Vivian Sobchack, "Nostalgia for a Digital Object: Regrets on the Quickening of Quicktime," in Millenium Film Journal 4-23, No. 34 (Fall 1999) and Norman Bryson, "Summer 1999 at Tate," available from Tate Gallery, 413 West $14^{\text {th }}$ Street, New York City. Bryson writes: Though the [computer] screen is able to present a scenographic depth, it is obviously unlike the Albertian or Renaissance window; its surface never vanishes before the imaginary depths behind it, it never truly opens into depth. But the PC screen does not behave like the modernist image, either. It cannot foreground the materiality of the surface (of pigments on canvas) since it has no materiality to speak of, other than the play of shifting light." Both Sobchack and Bryson stress the difference between the traditional image frame and the mulitple windowns of a computer screen. Finally, Brayson adds, "the whole order of the frame is abolished, replaced by the order of superimposition or tiling."
} 
The photograph, however, is embedded with the documentation of something that existed. Its reality is rooted, or at least the parts of reality, in what is deemed important by the photographer. Rather than being a neutral conduit for presenting information, the screen is aggressive. It functions to filter, screen out, and take over, rendering all outside of the frame non-existent. Of course, this filtering degree varies between cinema viewing and television viewing or between smartphone and computer viewing.

Appearing here is the genealogy of the screen, according to Manovich, used in the same way that we will later apply the genealogy of keys / buttons as according to Vilem Flusser. Manovich provides the lens through which we discuss the effect of digitized images on the user and its effect on their eternalizing of that visual information; and how that understanding impacts the creative objects that they produce. The connecting tissue of these two modes of thought is their relationship or indexical qualities that physically connect flesh to our digital landscape: Buttons. The buttons link the bodies on the ground and the bodies in the air. Flusser's understanding of buttons or keys is the digitized rendering of Graw's argument of indexicality within mark-making. It is the philosophic lens to analyze digital mark-making. Where Graw provides that history and a sense of loss dictates a compulsion to paint rejectively—to paint whilst rejecting painting. Flusser argues that it is our designed digital infrastructure that 
indicates how we design and distribute images. I utilize them together to argue that our tools mirror how we ascribe responses to the world. And it appears that those tools have a high amount of connections to the U.S. military.Based on the U.S. and British involvement in developing images and their connection to violence, our future appears troubling. One of the quesitons that this exhibition asks is, how do we disentangle our media from the violence it is tied to?

Manovich describes the screen and our body's relationship to it as one as "centered around temporality." Appearing as a psychological experience, perceptions are doubled, or cut. He describes the varying modes of screens, a description we will follow from here forth, as a (1) a classical screen which "remains static and is a permanent image," (2) a dynamic screen which "displays a moving image of the past," and the (3) real-time screen which displays the present. The connective experience between the classic, dynamic, and real-time screens is the knowledge of each is cut by the rectangle of the screen." ${ }^{36}$ This act of "cutting" reality simultaneously doubles the viewing subject, which now exists in two spaces: the familiar physical space of her natural body and the virtual space of an image within the screen. This split comes

\footnotetext{
${ }^{36}$ Manovich, 103.
} 
to the surface with VR as well as mixed reality, but it already exists in painting and other dioptric arts." 37

${ }^{37}$ Manovich, 104. 


\section{THE SCREEN, RADAR, AND THE MILITARY}

There is a whole field of study linking radar to photography, camouflage, and the screen, but we won't grant it too much time. Manovich contributes to this field in The Language of Media (2001) and "Automating Aesthetics: Artificial Intelligence and Image Culture." (2017). It is important to note here as it is a part of the interactive screen's genealogy, which contributes, later, to our examination of Post-Digital Painting. To summate, the reason for radar's effectiveness: the new means of displaying an image, a new type of screen." 46

The importance of radar is its relationship to time-which is different from that of photography or cinema-for these two conceptualizations of the screen can only show past events and are reliant on static experience. Next to photography, radar supplied a superior way to gather enemy location intelligence. In the mid1950s, amidst the Cold War, MIT worked with the Air Force to open a secret laboratory the Lincoln Laboratory. The Lincoln Laboratory's purpose was to work on human factors and new display technologies for SAGE, or "Semi-Automatic Ground Environment." According to Paul Edwards, historian of computer technology, SAGE's job "was to link together radar installations around the USA's perimeter, analyze and 
interpret their signals, and direct crewed interceptor jets toward the incoming bee. It was to be a total system, one whose "human components" were fully integrated into the mechanized circuit of detection, decision and response." ${ }^{47}$ Manovich observes that with radar, we see the mass employment of a fundamentally new type of screen for the first time, a screen that gradually comes to dominate modern visual culture - the video monitor, computer screen, and instrument display." ${ }^{48}$ What is new about such a screen is that its image can change in real-time, reflecting changes in the referent, whether the position of an object in space (radar), any alteration of visible reality (live video), or changing data in the computer's memory (computer screen). ${ }^{n 9}$ The image is updated in real-time, and the user can manipulate it. The user has limited control of the screen's change or output - rather than being continuously controlled by the forces that designed the image. Yes, the screen changes in real-time in response to code that dictates its display and displays our actions. The actions or functions existing within the screen are, beyond encrypting or hacking, predetermined and predesigned. That which is manifested is finite and preformulated. If we are positioned as a society of the spectacle or culture of the simulation, then spectacles and simulations are synchronous due to our relationship with screens. This screen description will be essential when discussing Flusser's 'keys' and Post-Digital Painting. 
The Screen is always intimately tied to painting (in its language) and war (in its advancement financing). Paul Edwards sees computers and the screen, specifically, as "a common denominator in constantly changing social constellations within academic research, engineering practice, industrial aims, and political interests." ${ }^{38}$ The military and its subsequent enterprises have been the deciding factor in what Vilem Flusser argues designs our technical images. Edwards is pointing to computers, specifically, as being a tool that contributes broadly to academic inquiry. Those buttons, platforms, interfaces, that make up our digital environment have been cultivated, expressly, by the United States military. Edwards argues that this makes these tools part of a closed-world discourse. Implying that the "languages, technologies, and practices support the centrally controlled and (semi)automatic United States in the nuclear age through the concepts and expansive practices of cybernetics, artificial intelligence, and cognitive psychology." ${ }^{39}$ As much as this applies to cybernetics, AI, and psychology - it also applies to aesthetics. Our tools that are financed by the military are contributing to the way artistic objects are fabricated.

\footnotetext{
${ }^{38}$ Eriksson, Kai. "The Closed World (Book)." Acta Sociologica (Taylor \& Francis Ltd), vol. 41, no. 4, Dec. 1998, pp. 399-401. EBSCOhost, doi:10.1177/000169939804100418.

${ }^{39}$ Eriksson. 401.
} 
Not only that, but to how we are influenced and stimulated to make aesthetic objects.

This is a weight that shouldn't be dismissed. 


\section{VILLEM FLUSSER: TRADITIONAL AND TECHNICAL IMAGES}

Flusser's composition is complicated and often dismisses the reader's

understanding in preference of abstraction.

Using multiple languages interchangeably and distinctive in his

approach, Flusser is challenging to decipher. Upon acknowledging this, his abstraction and idiosyncrasy allow this text to introduce science fiction's approach to understanding data - mythologizing. Here, we can begin to understand the chronological development of images and language through syntax that is more imaginative and less objective. Flusser utilizes mysticism and magic interchangeably with pragmatic analysis, as we will be towards the end of this document.

Critical image theory accurately conceptualizes the politics involved in image production and consumption. It recognizes an integral part of making images are buttons. The symbolic objects attached to the phone, the keyboard, and the camera shutter's tap are all tools that instantly document. Keys function to record images or language, thoughts, or observations. Flusser finds the key -- the physical button created to communicate an action between a photographer and the camera -- or a typist and a computer; works both as a signifier and an extension of the author, in the same manner, that Graw would argue the brush or hand tool used by a painter is an extension 
of the author. Flusser states that while affording a creative opportunity to the author, the button or key stipulates parameters for making. The 'key' functions as a liaison between the author and the document - be it image or text.

We are in a state of 'technical images,' which is connected to the use of keys. Flusser defines such as distinct from what he refers to early pictures or what we will be referencing as 'traditional images.' Traditional and technical images vary in many ways but, ultimately, "the difference between traditional and technical images is that the first are observations of objects, the second are computations of concepts. The first arises through depiction, the second through a peculiar hallucinatory power that has lost its faith in rules." 40 Technical images "rely on texts from which they have come and are not surfaces but mosaics assembled from particles. Technical images arise to consolidate particles around us and our consciousness on surfaces to block up the intervals between them to make elements such as photons or electrons, on the one hand, and bits of information, on the other hand, into images. ${ }^{41}$

It is always with tools that we extend ideas - these tools include hands, stone, fire, brushes, etc. Tools that predicate our making control how thoughts manifest by their

\footnotetext{
${ }^{40}$ Vilem Flusser. "Into the Universe of Technical Images." University of Minnesota Press. 2011. Pg 10. Accessed 2018 http://cmuems.com/excap/readings/flusser-into-the-universe-of-technical-imagesexcerpts.pdf

${ }^{41}$ Flusserr, 16.
} 
design and function. Flusser states that these apparatuses that humans have designed don't allow for contemporary designs to "be achieved with hands, fingers or eyes and, for this reason, devices must be developed that grasp the ungraspable, visualize the invisible, and conceptualize the inconceivable. These apparatuses must be fitted with keys so that we may manipulate the imaginary. If we are indeed in a period of technical images, then these apparatuses are essential to producing; and must be required to open us up to new possibilities unimagined within human capacity. If they limit us by their limitations, they must afford observations yet unimaginable. All the rest comes after.

If we apply this lens to digital interfaces, application software ${ }^{42}$ functions in the same way as keys on a keyboard, buttons on a camera, or brushes loaded with paint. To return to the Manovich, "applications offer new-media creators the opportunity to work with new tools, [but] they nonetheless still predicate the relationship or the product come by their design. They act as "another filter which shapes the imagination of what is possible to do with a computer." ${ }^{.55}$ We can make this an additional step and add that the software, mouse, and keyboard (or keys) can cultivate an image, as referenced, in addition to interactive screens,

\footnotetext{
${ }^{42}$ program or group of programs designed for end-users. An end-user is a person who ends up using a particular product. Examples of an application (or colloquially referred to as an app) include a word processor, a spreadsheet, an accounting application, a web browser, an email client, a media player, a file viewer, simulators, a console game, or a photo editor.
} 
images, and text that change in real-time. The button is the liaison between the signified and the signifier. Utilizing any one of these unleashes a reaction that is invisible to the user. When I press "i" on my keyboard, I do not have a direct and quantifiable experience that explains the connection to my pressing a button and the letter "i" appearing on my screen. The only time I contemplate it is when there is a delay between my action and the formation of a 'reaction' on said screen. 


\section{CRITICAL IMAGE THEORY}

Earlier in this text, we briefly touched on Pierre Bourdieu's theory of cultural capital. We return to this idea to begin to grapple with a production of images as a tool of social and upward mobility. Bourdieu explains cultural capital as a symbolic propagation of social status through the association of a brand or class. ${ }^{43}$

Additionally, an outsider of a particular social class can share similar symbols, alluding to inclusion with the goal of social mobility. Evidence of this phenomenon amongst social media platforms has been written to death, but most recently, it is evident in internet trends such as the market boom in $\mathrm{NFT}^{44}$ sales. Bourdieu's theory moves capital from material items and social exchanges to images -- more importantly -- image sharing. For example, Lev Manovich, discussed extensively prior, expanded on Bourdieu's ideas by applying them to Instagram and analyzing its internal image culture. Manovich explains that various features of a 'popular' image become the target of reproduction for other users to garner

\footnotetext{
${ }^{43}$ David Throsby. "Cultural Capital." Journal of Cultural Economics. 23, 1-2 (1999) p 3-12. December 2020

${ }^{44}$ Non-fungible tokens or NFTs are cryptographic assets on the blockchain with unique identification codes and metadata that distinguish them from each other. Unlike cryptocurrencies, they cannot be traded or exchanged at equivalency. This differs from fungible tokens like cryptocurrencies, which are identical to each other and, therefore, can be used as a medium for commercial transactions.
} 
cultural capital. ${ }^{45}$ Later in "Post-Digital Painting," we'll see how social media has undoubtedly proven influential in producing painted images and objects.

Theorists such as David Joselit go so far as to say that the use of images for cultural capital has a socio-political impact. Provided they can accumulate associations across similarities, which impacts media, economy, and global politics. A contemporary example being the current bills passing through the house banning "noknock warrants" after a year of organizing and protesting within the most significant movement in United States history, on behalf of Breonna Taylor (and George Floyd), who was murdered by police in her home in Louisville, Kentucky in March of 2020. This movement was heavily organized through IRL organizing and communicated through various social media outlets and encrypted messaging applications such as Signal and Threema. In other words, adjunct to organizing efforts, social media sharing of marches, community meetings, and rallies contributed to the passing of legislation.

Jacques Rancier's The Future of the Image asked evolving questions in the field of critical image theory, such as the quandary of whether there are any more images or if we are in a state of reality that relentlessly represents itself to itself. In other words, are

${ }^{45}$ Lev Manovich, "Instagram and Contemporary Image." Manovich.net. New York. 2016. Dec 2020 
we in a state of memorized regurgitation of historical images that quasi-stimulate media events, social behavior for documentation, and political evolution? The coalescence recalls the infinite back and forth between camouflage development, the camera, and the screen. The acts of hiding and announcing, hunting and documenting, are paramount and metaphor to documenting historical events and our response to them. It is also important to consider: Reality representing itself to itself harkens back to our discussion of emotional reactions to 'the death of painting' after Postmodernism and the subsequent anti-market response found in Casualist discourse. Casualism "hides" its value by camouflaging its worth in deskilling to disincentivize the commodified painting. There is an action, and there's always a reaction. We also see this mirrored reality in the Gaddafi paintings discussed in "Isabelle Graw and Indexical Painting." Assuming Ranceire is correct in his theory, this is evidenced by the oscillation between figurative documentation and the abstracted, gruesome, and materially centric abstractions of Gaddafi's corpse in Wilhelm Sasnal's Gaddafi (2011) paintings. It's also evident in the mimicked painting found in "The Incredulous Thomas" (2019) and "THERE WAS NO TEMPLATE" (2019-2021), found here in this exhibition. For both works, painting and deceit oscillate between what is and what isn't painting, mirroring the effect of 
mimicking space and news through media that no longer serve a purpose of

communication. The impact of mimicry and misdirection is the thread connecting these materials to their origination - and the frustration that that effect, and oscillation

stimulate. 


\section{CONCLUSION: CASUALIST PAINTING, THE MILITARY, THE SCREEN}

I acknowledge that this information seems distanced from one another. To summate, in this exhibition, we see camouflaged mark-making and activities announce or shield meaning from the viewer. In works such as "The Sky Starts at Your Feet" (2020), we see full advertisements from the New York Times' "Truth Campaign" (2016) ${ }^{46}$ appropriated and thus call to question where meaning and 'truth' lie in our media. I am directly asking the viewer to consider how they receive visual data using camouflage and appropriated media as a metaphor for finding meaning in our images consumed during screen time.

\section{but also full of seeds for a future that could have turned out}

differently also contains many textiles that had holographic inkjet-printed patterns applied to them. The use of holographic materials is essential because the holograph is the one item in this exhibition that did not evolve within the military. Instead, it was invented in 1947 by Dennis Harbor and wasn't utilized within the U.S. military until the 2010's when the Obama administration began using holographic technology in mapping drone strikes. ${ }^{47}$ Because of its development outside of the military, it feels safer, even utopian.

\footnotetext{
46 "The Truth Campaign" was a series of advertisements designed by Droga5 for The New York Times, advocating for "truth" in lieu of misinformation and propoganda uptick after Donald Trump took Presidential office in 2016. The ads are criticized in this exhibition as using footage of migrant children and, specific to this installation, the Rohingya being persecuted in Myanmar in order to sell newspapers. Link to the advertisement: https://www.youtube.com/watch?v=PZJdKuTRN5E

${ }^{47}$ David Hambling, "Fighting Shadows: Military Holograms." Military.com. 2006. https://www.military.com/defensetech/2006/11/24/fighting-shadows-military-holograms. Accessed April 2021.
} 
This utopian nature of the holograph links this exhibition to digital interfaces that I am beginning to employ in upcoming projects and briefly discussed to conclude this thesis. What is an ending without another beginning? 


\section{POST-DIGITAL PAINTING}

We are in a Post-Digital Age. Christine Paul, the Whitney's adjunct curator of digital art, notes in the curatorial essay "Programmed: Rules, Codes, and Choreographies: 1965-2018," for the exhibition, Histories of the Digital Now (2019), at the Whitney Museum of American Art, describes the word "programmed" as one typically associated with digitality, but this is not inherently true. Paul is quick to state that artists have used programs - rule sets and abstract concepts to create their work, employing mathematical principles to drive forms and ideas or establishing rules to explore structures and colors for ages. ${ }^{48}$ Paul notes that, yes, 'digital art' is typically that which was "digitally born,” work that is created, stored, and distributed via digital technologies. What makes this moment one of post-digitality is that, at risk of generalizing, most contemporary art uses the applications and tools of production supplied by digitality at some point in its production. Photography, research, and editing tools of production such as 3D printing, all impact and effect methodologies of making. As French philosopher Bernard Stiegler states, all domains are being technicized, and it is happening on a massive scale.

The subject of painting is of special credence here. There are the heavyweights of post-digital painting, the Trudy Benson's, Will Hutnicks, Christopher Wool, and others. Mostly young and working in abstraction, these artists tend to employ the same reference to flatness afforded by the screen. Depth is simulated by layered

\footnotetext{
${ }^{48}$ Christine Paul. "Histories of the Digital Now." Programmed: Rules, Codes, and Choreographies in Art, 1965-2018. Whitney Museum of American

Art. https://whitney.org/essays/histories-of-the-digital-now. Accessed 2020.
} 
planes and vague imitations of shadow that recall chiaroscuro. Flatness is truncated by marks and employment of editing applications such as Adobe Photoshop, adding shapes that layer without reference to space, and erasures that relocate the viewers' perception of what planes are in front of each other. In but full of seeds for a future that could have turned out differently this is shown, directly, in the excerpts from the series, it was a thing of thickness with no leg to stand on (2018-2021), large decals ${ }^{49}$ are adhered to the wall alongside a trompe l'oeil drop shadow. Under the right circumstances, these photoshop collages (consisting of images sourced from my paintings, Wikipedia images, and lowquality Google Search images of Master Paintings) read like a painting from across a room. They are rendered and conceptualized from IRL material, broken down, coded, digitally printed, and adhered to the wall.

These works are obviously of the post-digital family, but they are also rendered economically obsolete by their destiny in a recycling bin. Their existence is momentary at best, and thus they become Post-Digitally Casualist. They render their commodity status obsolete, or at least irrelevant, while also being of painting without materializing as such. Using paintings' indexical qualities - marks that hold the same viscous descriptors as paint, there is the act of intentionally camouflaging-copying the marks of digital mark-making technologies to cultivate an oscillation between IRL marks and digital marks.

49 stickers, to be removed and recycled after installation 


\section{COPYING DIGITALITY: HOLOGRAPHIC TEXTILES, LIGHT MISDIRECTION,}

\section{AND UTOPIAN ANTI-MILITARISM}

Operating under the assumption that the military’s lack of use invokes a moral

innocence to the holograph, then the holographic textile is the utopian answer to

misdirection in camouflage. Its utopianism arrives at its non-weaponized structure, its

lack of utility in surveillance and reconnaissance until recently. ${ }^{505152}$ It allows me

to use the holograph ethically - referencing misdirection and deceit while not directly

deceiving the audience or using unethical images. For clarity's sake, an unethical image

is categorized one of two ways in this document: (1) an image (such as an advertisement)

that uses documentation of marginalized, victimized, or brutalized people to arouse

empathy in the viewer in a way that it may stimulate consumerist activity. Thus, the

maker of the image is able to profitize the imagery of victims. (2) Using images that

directly deceive the viewer.

Holography is means of creating a unique photographic image without the use

of a lens. ${ }^{53}$ It is a real-world recording of an interference pattern that uses diffraction to

\footnotetext{
${ }^{50}$ In 2010 it was announced that the U.S. military was attempting (or getting close) to developing holographic technology for mapping battlegrounds, but nothing has been fully disclosed as to its success rate for long range battle. But this is relatively remarkable considering that the technology was invented in the 1930's. This is a rare disconnect between available technology and its implementation on the battlefield.

51 2006, 24 Nov. "Fighting Shadows: Military Holograms.” Military.com, 24 Nov. 2006, www.military.com/defensetech/2006/11/24/fighting-shadows-military-holograms.

52 Trade Show Hologram. "Hologram Projector at Military Trade Show.” YouTube, YouTube, 19 May 2010, www.youtube.com/watch?v=XYy-bYhUglo.

53 Britannica, The Editors of Encyclopaedia. "Holography". Encyclopedia Britannica, 29 Apr. 2019, https://www.britannica.com/technology/holography. Accessed 30 January 2021.
} 
reproduce a 3D light field, resulting in an image that maintains the depth, parallax, ${ }^{54}$ and other properties of the original scene. A hologram is a photographic recording of a light field rather than an image formed by a lens. When comparing holography ${ }^{55}$ to photography: a photograph is a record of the variations in intensity of light reflected from an object, producing dark areas where less light is reflected and light areas where more light is reflected. However, a holograph records the intensity of the light and its phase or the degree to which the wavefronts making up the reflected light are coherent. Ordinary light is incoherent-that is, the phase relationships between the multitude of waves in a white light beam are entirely random; wavefronts of ordinary light waves are not in step. However, a laser beam, as one example, is controlled. Its waves are symmetrical and predictable.

Holographic inkjet prints on commercially available textiles are used in this exhibition. The holographic inkjet maintains the illusion of self-lighting. Its ability to alter our perception of color depending on our bodies' placement and the textiles' response to light allows for a specific mimicry of experience. An experience identifiable in our experience with screens and painting. Theoretically, this haptic relationship between the object (the painting) and the viewer stimulates a synchronous excitement and instability. An uncanny dichotomy - the relationship between light, space, and our understanding of material converge to produce a feeling of knowing and unknowing. This announcement of presence symbolically ties this work to the history of

\footnotetext{
${ }^{54}$ a displacement or difference in the apparent position of an object viewed along two different lines of sight, and is measured by the angle or semi-angle of inclination between those two lines.

${ }^{55}$ Diffraction refers to various phenomena that occur when a wave encounters an obstacle or opening. It is defined as the bending of waves around the corners of an obstacle or through an aperture into the region of geometrical shadow of the obstacle/aperture. The diffracting object or aperture effectively becomes a secondary source of the propagating wave.
} 
camouflage and the oscillation between the historical reference to that hiding of place and the seeking of intelligence that we found in the chapter Camouflage and Photography: Meaning Hidden, Removed, and Shown.

The unstable nature of the textiles is also worth mentioning. The variable nature of lycra: its ability to stretch, sag, and crumble, makes this an unsavory source with which to apply paint. The lifespan of these objects is unknown. Their reliability as structures is as founded as is the sphereified watercolor paint is stable. These objects can be purchased, but their lifespan is unknown. As painting is commodified and regarded as an investment object, these aren't the wisest purchase. Their paint will stretch and peel from the surface, be prone to cracking and other destabilizations. Like the sphereified watercolor, the paint will change, and the object's livelihood will faltertheir instability and subject to change make their purchasability an unsavory one.

Though these paintings are unsavory commodities when considered for their longevity, their reliance on the holograph has been of continued interest. The holograph, replicating the experience of interacting with a screen, combined with anti-illusionistic mark-making that references the marks made in photoshop, makes these post-digital objects. 


\section{WHAT ABOUT THE TWENTY-SECOND CENTURY}

In the fall of 2020, I began designing a web platform that collects data on what various United States residents believe twenty-second-century democracies would look like. In lieu of making work destined for a gallery, I felt that utilizing the accessibility of the internet was more conducive to my interest in open source subjectivity. More specifically, what does the public think, and how could I use 'artistic endeavor' to cultivate a safe place for individuals to place their political observations. Would this data be of use to anyone: Political Scientists, Sociologists, Data Visualists? How can I contribute to utopian data mining? How can I contribute more broadly to a more rhizomatic and democratic field study that benefits researchers and the public alike? What comes below is the conclusion of this body of work and the entrance to the next. It is a projection and an outline of a qualitative survey that I hope to continue developing during my time at University of Chicago's Department of the Digital Humanities.

I am designing a qualitative survey that collects data from the public about how they visualize the democracies of the twenty-second century and, more broadly, how they characterize "the future." What are the first steps? Where would they like to start? This project's design will coincidentally supply whether the public is thinking about or considering this idea based on whether individuals choose to participate.

This data matters for two reasons: (1) it provides the opportunity for anyone interested in the subject to participate, and (2) as with any discussion of the "Utopia," the 
recognition of its impossibility is integral, but using it as a goal post for social, ecological, and philosophical benefit is a great starting point.

My philosophies regarding art predicate that it is the artist's responsibility to bring to light or mirror to the public that which they intuitively understand, but perhaps don't factually know, have the time to investigate for themselves, or understand how to critique. In juxtaposition to this philosophy is my worry that in attempting to educate, artists stifle public engagement with radical material—radical material that has provided more than gratuitous evidence that art stimulates newfound ideas that end up enriching and bettering the lives of the people it directly activates as well as those that are indirectly affected. My answer to this is to place the responsibility of imagining into the audience's hands. Rather than the gallery, or any public forum, as a place for consumption. Defining Utopia

The term "utopia" has a long, toiled, and sought-after history in fiction and philosophy. Starting with Sir Thomas More's text Utopia (1516) from the Greek ov̉ ("not") and $\tau$ ó existent societies. Recognized as an impossibility, it has left philosophers, authors, and artists bemused and perplexed since its inception. Ernst Bloch, Friedrich Hegel, Theodor W Adorno, Lukáš Perný, Alexander Hamilton, and Karl Marx, to name a select few. Here we'll use the definition set forth by Immanuel Wallerstein, an American sociologist and economic historian. In his text, "Marxisms as Utopias: Evolving Ideologies," Wallerstein relates what he refers to as the successive eras of Marxian thought as they pertain to the utopia construct: "The three definitive texts [regarding utopia] are by Thomas More, Friedrich Engels, and Karl Mannheim. They are, respectively, utopia as the criticism of 
capitalist reality in the name of egalitarian ideas, as the culminating idea of the bourgeoisie's "kingdom of reason," and as a state of mind that can "transcend reality. . . [and] break the bonds of the existing order." ${ }^{70}$

Wallerstein has further elaborated on how he finds the utopia to function. After analyzing and acknowledging the limitations of utopias in a revision of the paper cited above, in Unthinking Social Science: The Limits of NineteenthCentury Paradigms, Wallerstein pushes the term into a new direction - utopistics. Wallerstein defines this study as something mildly different. "Utopistics is the serious assessment of historical alternatives, the exercise of our judgment regarding the substantive rationality of alternative possible historical systems. The sober, rational, and realistic evaluation of human social systems, the constraint on what they can be, and the zones open to human creativity. Not the face of the perfect (and inevitable) future, but the face of an alternative, credibly better, and historically possible (but far from certain) future." ${ }^{56}$ It is this definition of 'utopia' that this project relies upon. Not the fantastic 'utopia' of More's inception, but a rational and realistic comprehension and critique of our current systems.

Though "What About the Twenty-Second Century" relates explicitly to Utopia Station (2003), the namesake comes from the Venice Biennale's curatorial statement. Francesco Bonami, the Director of the Biennale in 2003, proclaims the following: "I feel very strongly about advocating creative irrelevance to attack the absurdity of war, violence, and discrimination. I am for producing dreams to contain the madness of conflicts. An exhibition like La Biennale di Venezia

\footnotetext{
${ }^{56}$ Wallerstein, Immanual. "Marxisms as Utopias: Evolving Ideologies.” Unthinking Social Science: The Limits of Nineteenth Century Paradigms. Cambridge, Polity Press. 1991. 170-84.
} 
acquires power as a symbolic ground for workable solutions. The "Grand Show" of the $20^{\text {th }}$ century was developed from the single perspective of the curator / author. But the "Grand Show" of the $21^{\text {st }}$ century must enable multiplicity, diversity, and contradiction to exist within the structure of the exhibition. It must reflect the new complexity of contemporary reality, vision, and emotions. Dreams and Conflicts: The Dictatorship of the Viewer offers the viewer's eye and imagination a complex world transformed by the eye and imagination of the artist. It offers a world where the conflicts of globalization are met by the romantic dreams of a new modernity. [Joseph] Beuys said that we all are artists. Although not all people may recognize this, we are all in charge of our own experience and imagination. We all strive to reach that creative tension between our inner spirit and the utopian safety of our daily life." ${ }^{57}$

In other words - absurdity and discord are the magnitudes appropriate for an attack on the madness of war, violence, and discrimination. Bonami wanted to "offer the viewer's eye and imagination a complex world transformed by the eye and imagination of the artist." But what about the viewer's imagination? Where does it stand in discourse? Where does the public's complex world get to be discussed or pondered? Where and when do we have the opportunity to voice concerns, hopes, fantasies, and imaginary utopias for each other to consider? Perspectives from outside of academia or activist circles can be invaluable to researchers, theorists, artists, and philosophers alike. It's a source of data that is rarely relied upon. The freedom in referencing the imagination is

\footnotetext{
${ }^{57}$ Francesco Bonami. “Curatorial Statement.” Dreams and Conflicts. The Dictatorship of the Viewer. 50th International Art Exhibition La Biennale di Venezia. (Veggiano, Grafiche Peruzo, 2003) p 1.
} 
that the act of imagining is not a skill acquired by training or access to education. It is innate and free.

Bonami claims that placing the power of discussion in artists' and curators' hands is imperative to the twenty-first century. For me, this begs the follow-up question of, well, what comes next? What about the twenty-second century? If the power to persuade, or the "Grand Show," as Bonami references, was developed from the curator or author's single perspective. The twenty-first century's "Grand Show" becomes about diversifying that power. What comes next if we follow a chronological diversifying of 'authors?' Who will be granted strength and access in the twenty-second century? Bonami's logic argues that this will be the time of the viewer. Artists and authors diversify and democratize voices via granting platforms and opportunities for anyone to contribute to a centralized idea - an example being their version of a Utopia.

\section{Utopia Station}

"what_about_the_22 ${ }^{\text {nd }}$ _century. space" works as a virtual installation and data collector in conversation with the dozens of in-person exhibitions, architectural fairs, virtual exhibitions, and lectures that have worked as veins coming from one primary exhibition - Utopia Station (2003). Utopia Station was an exhibition originally installed at the 2003 La Biennale di Venezia, Dreams and Conflicts: Dictatorship of the Viewer, mentioned above. The curator's Molly Nesbit, Hans Ulrich Obrist, and Rirkrit Tiravani worked with over 100 artists and collaborators to cultivate the mechanisms and visual cues of activist spaces to encourage unmitigated dialogue and activities that stimulated a radical envisioning of the "utopia." The curators used the impossibility of the 'utopia' as a tool to push the needle towards a new leftist society. 
There has been an uptick in designed projects utilizing the internet in a similar capacity to "what_about_the_22 $2^{\text {nd }}$ century. Space." Tally Saves the Internet is one example. TSI is a browser extension recently released by Sneakaway Studio, a collaboration between artists Joelle Dietrick and Owen Mundy, which builds online interventions, animations, and mobile apps to reimagine a more sustainable and equitable digital future. Concerned about the unintended consequences of automated systems, their creations break apart and reconfigure existing structures to build awareness of physical and digital infrastructure. ${ }^{58}$ Their project, Tally Saves the Internet, is a browser extension that transforms data advertiser's collections into a multiplayer game. Once installed, a friendly pink blob named Tally lives in the corner of the users' browser screen and warns them of companies translating their human experiences into free behavioral data. ${ }^{74}$ The protagonist of the game, Tally, when encountering a "product monster," announces the 'monster' to the user so they can 'capture' them in a turn-based battle, transforming the game into a progressive tracker blocker where the user earns the right to be let alone through a playful experience. During a panel discussion at the 2020 SECAC conference, one-half of Sneakaway Studio proclaimed that this game is a reminder that internet experience is human-made. It can be improved for the betterment of its users. They continued to add that it is essential to introduce the public to 'surveillance capitalism' 59 as a concept that can

\footnotetext{
${ }^{58}$ Joelle Dietrick and Owen Mundy. “About”. Sneakaway Studio Artist Website. https://sneakaway.studio/about. Accessed December 2020.

59 an economic system centered around the commodification of personal data with the goal of profit gains.
} 
be managed democratically if an effort is applied. Pushing that if [internet users] understand our system, we can critique it and improve upon it." ${ }^{60}$

Similarly, also to Tally, "what about the $22^{\text {nd }}$ century" uses its platform as an avenue for educating users on specific content in addition to its particular purpose. What about the $22^{\text {nd }}$ Century provides the user/participant the opportunity to bump into information about projects regarding utopian ideas around housing, transportation, and utopistic paradigms. Where "What About the $22^{\text {nd }}$ Century?" differs from the exhibitions and online programming is its appropriation of social research methodologies. Where Tally Saves the Internet uses the multi-user game, and Utopia Station used tools of direct action, organizing, and protest spaces: tents, free talks, pamphlets, temporary installations, etc.; "What About the $22^{\text {nd }}$ Century?" uses the qualitative survey as an operational symbol to discuss the future with an anonymous audience.

I am not setting expectations for the collected data. Setting expectations in this specific context would place the data on a failure to success binary that I do not believe will help this data set. I am, instead, relying on the power of pattern and induction that I hope to appear in the collection. At the risk of contradicting myself, I do theorize that there will be a pattern of the following words, which are listed in no prioritized order: (1) democracy, (2) fascism, (3) green energy, (4) dystopia, (5) technology, (6) utopia, (7) socialism, (8) oppression, (9) hope, (10) distress, (11), water, (12) human rights, (13) fascism, (14) space travel, (15) and the United States. I theorize that these words may appear due to their relation to utopias and the future. Admittedly, this research

${ }^{60}$ Deitrick, Joelle. “Tally Saves the Internet.” Re(:)Thinking Space (Topic, Chars: Jeremy Culler, James Enos). SECAC 2020. VCUArts Commonwealth Virtual Conference. Zoom. Accessed December 2020. 
is entirely exploratory. Though these words have a higher probability of occurring in participant responses, I have no direct data to indicate a probability of that finding. The website will be accessed through a QR Code placed in diverse locations around the United States. I will rely on a rhizomatic distribution of decals containing the QR code. I will be sending four (4) individuals that are within my direct network. The people are trusted colleagues that are also artists, organizers, authors, and educators. Each person within six (6) specific United States cities or regions, receive a sheet of decals to be cut and dispersed to individuals of their choice. The decals were mailed with a small document with the following instructions:

"Hey _ _ the sheet of decals within this folder is to be cut into (9) 4" x 4" decals to be dispersed to whoever you would like. The only rules for this dispersal are (1) they have to stay within your city limits, and (2) the individual you hand the decal must report back where the decal has been installed. You will then report the location back to me, but not the individual who placed the decal. I would like those individuals to be anonymous to me."

Those individuals will then place the decals wherever they organically go. The only requirement is that they (1) cannot place the sticker outside of the region they have been assigned to represent. They must report back with the location that the decal was installed. The QR codes are specific to the cities they are being sent to, allowing for location measurement and context for the answers being received. The decal sheets were dispersed amongst the following cities or municipalities: Louisville, Kentucky, New York City, New York, Chicago, Illinois, Muncie, Indiana, Portland, Maine, and Seattle, Washington. These locations were chosen out of 
convenience, not locational value; I have contacts that I trust and have collaborated with in the past located within these locations. I expect some variability from each location, but I do not have specific expectations other than a vague sense that sites such as Louisville, Kentucky, and Muncie, Indiana will skew more conservative than, say, New York City or Chicago Illinois. This sensibility is only garnered from having lived in all four areas.

Once scanned by those motivated by the QR code, their device will navigate them to the website, where they are presented with the five essay questions and five poll questions. Hopefully, with this rhizomatically controlled sampling of data, I will gather a diverse collection of language from individuals, specifically non-experts, regarding what they believe the next century looks like.

As I am initiating a central data hub collecting the descriptive language provided by a diverse representative pool from various socio-economic, educational, racial, ability, and gender backgrounds, I am avoiding leading questions and other language that would stimulate or predicate participant responses. The questions are designed not to direct the participant in any specific direction. The second image they will be presented with is a photograph depicting an abandoned villa from Ai Weiwei and Herzog \& de Meuron's Ordos 100. Ordos 100 was an attempt in the early 2000s by the Chinese government and local Inner Mongolian municipalities to build a "New Ordos," a few kilometers south of the old city, which had seen substantial economic growth in the preceding decade. Their goal was to create a "flamboyant futuristic capital featuring state of the art architecture and acting as a new cultural, political, and economic center for the 
region." ${ }^{61}$ The Kangbashi New Area included giant cultural venues such as MAD's completed Ordos Mus, and landmark projects such as Herzog \& de Meuron and Ai Weiwei's Ordos 100 villas. At once hoped to be the Dubai of East China, the immense immediate investment in the multi-billions was causal of high property prices and resulted in a complete lack of interest by the public. Ordos 100, once a marvel contended by international superstars of architecture and public infrastructure planning, became a ghost town as quickly as it was conceived. Other examples found within the site include Auroville in Bengal, India, short films depicting an experimental program instigated by the Nixon administration that investigated the success probability of factory-built apartment building and images of quasi-feral lands as a contrast. ${ }^{62}$ These images, paired with text from the Utopia Station curatorial statement, provide nuance and a sense of space for the participant to rest within or explore before filling out the survey.

The survey appears in two assorted styles of survey taking. The first is a group of five (5) short written response questions. Those questions arise as follows:

1. what kind of world do we want?

2. Referring to the world you described above, that means or paths are we most likely to get there?

3. What would you change first?

${ }^{61}$ Howarth, Dan. “Ordos: A Failed Utopia photographed by Raphael Olivier.” De Zeen. 2016. https://www.dezeen.com/2016/01/10/ordos-a-failed-utopia-china-raphael-olivier-photo-essay/. Accessed September 2020 62 
4. Do you think change is sustainable if managed correctly? Is 'management' the correct term? Is there another approach to monitoring the change that you propose?

5. Utilizing your intuition or your gut, describe what you think established democracies will look like in 2117 ?

These short answer questions are followed by two sets of intentionally positively motivating quotes, followed by an image of Auroville's Health Center, currently active, but not evidenced by this photo. The five survey questions with answers on a scale of "strongly disagree," "disagree," "neutral," "agree," and "strongly agree" appear as such:

6. Greed is a very corrosive emotion, and our present system encourages; it even rewards it.

7. If honor and increased control of one's own work time were more generally available as rewards, people would find jobs more satisfying in replacement of money.

8. The destruction of property amounts to violence.

9. Some people, alive now, will see the next century.

10. The land belongs to no one.

The questions in the short answer portion are politically neutral. In contrast, the survey questions skew towards anti-capitalist sentiments - careful not to take specific positions on either side of the political spectrum — other than being outside of the center. For example, I've intentionally avoided topic specificity in favor of abstractions as it encourages open-ended responses from the participants. For instance, by avoiding 
discussions around green energy, the media, gun rights, or abortion rights, I avoid sentiments charged with contemporary politics.

The website "whataboutthe22ndcentury.space" received its domain registration and was designed within Squarespace Website Builder. When creating a webpage that includes any "form" feature or block, Squarespace automatically requires an email and has the option to link the stored answer with a Google Drive link provided by the author. Here, all input is collected in two different Google Drive Spreadsheets where simple "Ctrl F" functions can summate generated language once patterns are recognized amidst analysis by a coder. The survey poll, on the other hand, is presented within the website as "strongly disagree," "disagree," "neutral," "agree," and "strongly agree." On the spreadsheet, the answers appear as "-2, "-1," "0," "1," "2," respectively. The coder will simply regularly account for all input representations for each column, summating which responses appear at what percentage. The results of this collection will be deemed public access - meaning it is free to access and is designed to simply gather observations from many and given to whoever may find it helpful in their research, experiments, social organizing, theorizing, or any other form of intellectual labor that works as a catalyst for social betterment. I will not be placing any analytic framework on the gathered data other than summating various words that appear as linguistic patterns and give them regional context - and tally numbered responses to the survey data.

What About the Twenty Second Century, Conclusion

To conclude, I am designing a qualitative survey that collects data from the public regarding how they visualize the democracies of the twenty-second century and, 
more broadly, how they characterize "the future." I am interested in how they envision their future world beginning, meaning the first steps they would like us to start. Additionally, I am seeking data on the sustainability of those same ideas about the future, as described by the participant, assuming their idea is managed correctly. This project's design will coincidentally provide whether the public is even thinking about or considering this idea at all based on whether individuals choose to participate. Acknowledging that I am gathering data in an exploratory action with no natural end goal, the design is intended to provide public participants the opportunity to contribute. The design's primary function is to allow the participant the agency to describe what they imagine to be a better world. There are endless benefits to being given space and agency to safely declare your dreams, share your envisioned future, and feel interconnected to a more significant cause. If this design affords that to a few participants, then I designate it a success. 


\section{REFERENCES}

Francesco Bonami. “Curatorial Statement.” Dreams and Conflicts. The Dictatorship of the Viewer. 50th International Art Exhibition La Biennale di Venezia. (Veggiano, Grafiche Peruzo, 2003) p 1.

Pierre Bourdieu. ”Social Space and Symbolic Power.” Sociological Theory. 7, 1 (1989), 14-25. January 2021.

Sharon Butler. “The New Casualists.” The Brooklin Rail. June 2011 https://brooklynrail.org/2011/06/artseen/abstract-painting-the-newcasualists

Isabelle Graw, ” The Value of Liveliness: Painting as an Index of Agency in the New Economy.” Painting Beyond Itself: The Medium in the Post-medium Condition. Sternberg Press, 2016. P79-101. P 93.

Sharon Butler, “The Casualist Tendency.” Two Coats of Paint. https://www.twocoatsofpaint.com/2014/02/the-casualist-tendency.html

“Boilerplate Biography.” https://sharonlbutler.com/brief-biography

Joelle Dietrick and Owen Mundy. “About”. Sneakaway Studio Artist Website. https://sneakaway.studio/about. Accessed December 2020.

Deitrick, Joelle. “Tally Saves the Internet.” Re(:)Thinking Space (Topic, Chars: Jeremy Culler, James Enos). SECAC 2020. VCUArts Commonwealth Virtual Conference. Zoom. Accessed December 2020.

Paul Edwards, The Closed World: Computers and the Politics of Discourse in Cold War America. MIT Press, Cambridge Mass. 1989. P 142.

Kai Eriksson. “The Closed World (Book).” Acta Sociologica (Taylor \& Francis Ltd), vol. 41, no. 4, Dec. 1998, pp. 399-401. EBSCOhost, doi:10.1177/000169939804100418.

Vilem Flusser. ”Into the Universe of Technical Images.” University of Minnesota Press. 2011. Pg 10. Accessed 2018 http://cmuems.com/excap/readings/flusser-intothe-universe-of-technical-images-excerpts.pdf 
Vilem Flusser. Towards a Philosophy of Photography. Originally published in German, 1983. English-language translation, Reaktion Books, London. 2000. Pg 8-14. p8

Peter Geimer’s "Painting and Atrocity: The Tuymans Strategy. "Thinking Through Painting: Reflexivity and Agency Beyond the Canvas. Sternbereg Press. 2012.

Charlie Gere, "New Media Art and the Gallery in the Digital Age." Tate Papers. No 2. Autumn 2004. https://www.tate.org.uk/research/publications/tatepapers/02/new-media-art-and-the-gallery-in-the-digital-age. Accessed March 2021.

David Hambling, "Fighting Shadows: Military Holograms." Military.com. 2006. https://www.military.com/defensetech/2006/11/24/fighting-shadowsmilitary-holograms. Accessed April 2021.

Howarth, Dan. “Ordos: A Failed Utopia photographed by Raphael Olivier.” De Zeen. 2016. https://www.dezeen.com/2016/01/10/ordos-a-failed-utopia-chinaraphael-olivier-photo-essay/. Accessed September 2020

Helen Molesworth, ”Luc Tuymans: Painting the Banality of Evil.” in Luc Tuymans, ed. Madeline Grynszteijn and Helen Molesworth. (San Francisco: San Francisco Museum of Modern Art,2009),19.

Isabelle Graw, ” The Value of Liveliness: Painting as an Index of Agency in the New Economy.” Painting Beyond Itself: The Medium in the Post-medium Condition. Sternberg Press, 2016. P79-101. P80.

Xiaowei Huang. Understanding Bourdieu - Cultural Capital and Habitus. Review of European Studies. 45. 2019. 10.5539/res.v11n3p45

Catrin Lorch, Historienmalerei (History Painting) 2.0,” Suddeutsche Zeitung, February 3, 2012.

Lev Manovich, ”Instagram and Contemporary Image.” Manovich.net. New York. 2016. Dec 2020

Lev Manovich. “The Screen and the User.” The Language of New Media. MIT Press. 2001. P 94

Christine Paul. "Histories of the Digital Now." Programmed: Rules, Codes, and Choreographies in Art, 1965-2018. Whitney Museum of American Art. https://whitney.org/essays/histories-of-the-digital-now. Accessed 2020 
Alan Pocaro. "Provisional Painting: Three Hypothesis." Abstract Criticial. Jan 2015. https://www.alanpocaro.com/writing/2015/2/15/provisional-paintingthree-hypotheses. Accessed March 2021

Jacques Ranciere, The Future of the Image. 2019. 2 -

73. https://newsgrist.typepad.com/files/the-future-of-the-image-jacquesranciere.pdf. P 2. Accessed March 2021.

Raphael Rubinstein, “Provisional Painting,” ARTnews.com (Art in America, September 29, 2014), https://www.artnews.com/art-in-america/features/provisionalpainting-raphael-rubinstein-62792/. Accessed 2020

Rakesh Sharma. "Non-Fungible Token (NFT).” Investopedia. Investopedia, March 18, 2021. https://www.investopedia.com/non-fungible-tokens-nft-5115211.

Shell, Hanna Rose. Hide and Seek: Camouflage, Photography, and the Media of Reconnaissance. MIT Press. 2012

Hannah Rose Shell. "Mending the Net: Camouflage, Serial Photography, and the Suture of Self-Effacement and Reconnaissance." Hide and Seek: Camouflage, Photography, and the Media Reconnaissance. Zone Books, New York City. 2012. p 77- 126. P 77

Sneakaway Studios. “About”Tally Saves the Internet. https://tallysavestheinternet.com/about. Accessed December 2020.

David Throsby. ”Cultural Capital.” Journal of Cultural Economics. 23, 1-2 (1999) p 3-12. December 2020

Immanuel Wallerstein. "Marxisms as Utopias: Evolving Ideologies.” American Journal of Sociology. Vol 9. No 6. May 1986. University of Chicago Press Pg 12951308. P 1295

Immanuel Wallerstein “Marxisms as Utopias: Evolving Ideologies.” Unthinking Social Science: The Limits of Nineteenth Century Paradigms. Cambridge, Polity Press. 1991. 170-84.

2006, 24 Nov. "Fighting Shadows: Military Holograms.” Military.com, 24 Nov. 2006, www.military.com/defensetech/2006/11/24/fighting-shadows-militaryholograms.

Britannica, The Editors of Encyclopaedia. "Holography". Encyclopedia Britannica, 29 Apr. 2019, https://www.britannica.com/technology/holography. Accessed 30 January 2021. 
Britannica, The Editors of Encyclopaedia. "Arab Spring". Encyclopedia Britannica, 27 Jan. 2021, https://www.britannica.com/event/Arab-Spring. Accessed 2 April 2021.

“Provisional.” Merriam-Webster.com Dictionary, MerriamWebster, https://www.merriam-webster.com/dictionary/provisional. Accessed 17 Mar. 2021.

Trade Show Hologram. "Hologram Projector at Military Trade Show.” YouTube, YouTube, 19 May 2010, www.youtube.com/watch?v=XYy-bYhUglo.

“Zeitgeist.” Merriam-Webster.com Dictionary, Merriam-Webster, https://www.merriamwebster.com/dictionary/zeitgeist. Accessed 17 Mar. 2021.

The New York Times. “The Truth Is Worth It: Resolve | The New York Times.” YouTube, YouTube, 14 Jan. 2019, www.youtube.com/watch?v=PZJdKuTRN5E. 


\section{CURRICULUM VITAE}

NAME: $\quad$ Megan M Bickel

ADDRESS: Hite Art Institute

104 Schneider Hall

2301 S 3rd St Walk,

Louisville, KY 40292

DOB: $\quad$ March 22, 1990

\section{EDUCATION}

\& TRAINING: University of Louisville

2008-2009

Art Academy of Cincinnati

Bachelors of Fine Art

$2009-2012$

AWARDS: $\quad$ Outstanding Graduate in Fine Arts Award 2021

Digital Studies Scholarship (University of Chicago)

2021

Covi Award

2020

Arts and Sciences Graduate Teaching Assistantship

2019, 2020

Hite Assistantship

2018

\section{EXHIBITIONS}

(SOLO \&

TWO-PERSON): but also full of seeds for a future that could have turned out differently. MFA Gallery. Hite Art Institute,

University of Louisville.

2021 
What They Said In Public, Georgetown College. Lexington, Kentucky. 2020

_we_are_inside_the_fire_, Quappi Projects. Louisville, Kentucky. 2019

PLAY THAT ONE BACK, JOHNNY. Megan Bickel and Louis A. Edwards. Erie Art Gallery. Erie, Pennsylvania 2019

hope is grounded in memory. Hyland Gallery. Louisville, Kentucky 2018

Just Be Nice. Westheimer Gallery at the Sharonville Cultural Arts Center, Cincinnati, Ohio. 2015

I Just Want to Add. Semantics. Cincinnati, Ohio. 2015

\section{EXHIBITIONS}

(SELECTED GROUP): 40 Years: KMAC Museum. KMAC Museum, Louisville, Kentucky. 2021

The Shands Collection: New Directions. Curated by Julien Robson. Quappi Projects. Louisville, Kentucky.

2021

A(artistic) x (I)nterestingx(P)owerful. curated by Steve Kemple, Lindsey Whittle, and Loraine Wible, in conjunction with an A.I. Art Academy of Cincinnati, Ohio. 2020

Mental Misconceptions. Schneider Gallery. Allen R. Hite Art Institute. University of Louisville. Louisville, Kentucky 2019 
Future is Now. 849 Gallery / Kentucky College of Art and Design, Louisville, Kentucky. 2018

Structural Layers. Buckham Gallery. Flint, Michigan. 2017

Abstract Expressionism. Linus Galleries. Los Angeles, California. 2015

Modes of Abstraction, University of Cincinnati, Blue Ash Gallery. Cincinnati, Ohio. 2015

\section{PROFESSIONAL}

SOCIETIES Society For Collegiate Leadership and Achievement, University of Louisville Chapter.

Graduate Representative, United Nations Association (Women's League), University of Louisville Chapter.

Graduate Student Council, Fine Arts Representative, Research

Selection Committee. University of Louisville.

PUBLICATIONS

(PERSONAL):“Louisville Visual Artist Megan Bickel Works With Synthetic Materials, Confused Identities.” Tatiana Ryckman.

WFPL, NPR Louisville Syndicate. Louisville,

Kentucky. 2020

“Gerhard Richter Meets Lisa Frank in Louisville-Based

Multidisciplinary Artist Megan Bickel's Solo Bunk Spot Gallery Exhibition.” Steve

Kemple. Citybeat. Cincinnati, Ohio. 2019 
“_we_are_inside_the_fire_”. Ginger, Issue 19. Jacqueline Cantu,

and

Markee Speyer. Chicago / Bushwick. 2019

“Megan Bickel: Texture Study.” Werks: International

Contemporary Art. Chicago, Illinois. issue 2. 2019

“Artists to Collect: Megan Bickel”. Claudia Eng. 10011 Magazine in partnership with Claudia Eng Gallery. New York,

New York. 2018

PUBLICATIONS

(CONTRIBUTING

AUTHOR): Jordan Nassar and Joey Yates: The Field is Infinite, Interviews.

SECAC Journal Fall 2021

"Rebecca Norton: Q\&A." Ruckus Independent Art Journal. Louisville, Kentucky. 2020

“Q\&A: Kiah Celeste and Material Agency.” Aeqai. Cincinnati, Ohio. 2020

Tala Madani and her Théâtre de la Cruauté in Projections. Aeqai. Cincinnati, Ohio. 2020

The Double Standard and The Drawing Room within Perrotin A Quick Examination of Genesis Belanger \& Emily Mae Smith. Aeqai. Cincinnati,

Ohio. 2020

ALL THINGS ARE DELICATELY INTERCONNECTED: Jenny Holzer // Wanda Orme Earth Day and COVID-19. Aeqai. Cincinnati, Ohio. 2020 
Your Past Needs You: “Cat Mummies Came First” at Sheherazade. Aeqai. Cincinnati, Ohio. 2020

“We Don’t Have Anesthesia But We Have Music. . ." Feras Fayyad's "The Cave” (2019) at Speed Museum Cinema. Aeqai. Cincinnati, Ohio.

2020

“All the Useless Things Are Mine: A Book of Seventeens.” Ruckus Louisville. Louisville, Kentucky. 2020

September Diencephalon at Institute 193. Aeqai. Cincinnati, Ohio. 2019.

Letitia Quesenberry at Quappi Projects (((heat))) Louisville, Kentucky August 2nd - September 6th, 2019. Aeqai. Cincinnati, Ohio. 2019.

"Conspiratorial Aesthetics at the Cressman Center for Visual Arts: Why does so much new art look conspiratorial?” Aeqai. Cincinnati, Ohio. 2019.

Picasso to Pollock: Modern Masterworks from the Eskenazi Museum of Art at Indiana University at the Speed Art Museum. Aeqai. Cincinnati, Ohio. 2019.

\footnotetext{
Keltie Ferris: ${ }^{*} \mathrm{O} * \mathrm{P} * \mathrm{E} * \mathrm{~N} *$ at the Speed Art Museum: Casualist Painting / Not-cAsual SetTing Aeqai. Cincinnati, Ohio. 2018.
}

donottellmewhereibelong: drawing and sculpture by Joan Tanner Curated by Julien Robson Cressman Center for Visual 
Benjamin Cook: History Abridged at Swanson Contemporary, Louisville, Kentucky August 15th - September 22nd. Aeqai. Cincinnati, Ohio. 2018.

Artist Interview for Aeqai: Megan Bickel interviews Photographer, Bill Daniel. Aeqai. Cincinnati, Ohio. 2018.

Nick Cave: FEAT. // The Frist Center for Visual Art // Nashville, Tennessee.Aeqai. Cincinnati, Ohio. 2018.

A Brief Elaboration of a Tube: Letita Quesenberry and Aaron Rosenblum at Huff Gallery (Spalding University) Aeqai. Cincinnati, Ohio. 2018.

BRUCE CONNER: FOREVER AND EVER // Speed Art Museum. Aeqai. Cincinnati, Ohio. 2018.

Failure in Progress at Zephyr Gallery. Aeqai. Cincinnati, Ohio. 2018.

Symposia: Presenter.Third Annual Dr. Jonathon Riess Annual Undergraduate Art History Colloquium at University of Cincinnati. Cincinnati, Ohio. 2012 